\title{
Magnetic resonance imaging of pulse wave velocity in children aged 9 years to assess maternal influences on aortic stiffness in the offspring
}

\author{
Jennifer A Bryant ${ }^{1,2^{*}}$, Charles Peebles ${ }^{2}$, Mark A Hanson ${ }^{1,3}$, Sarah Crozier ${ }^{4}$, Hazel Inskip ${ }^{4}$, Sian Robinson ${ }^{4}$, \\ Philip C Calder ${ }^{3}$, Cyrus Cooper ${ }^{4}$, Keith Godfrey ${ }^{1,4}$
}

From 15th Annual SCMR Scientific Sessions

Orlando, FL, USA. 2-5 February 2012

\section{Background}

Pulse wave velocity (PWV) is an indirect measure of vascular stiffness. Higher PWV is a recognised cardiovascular risk marker. Magnetic resonance imaging (MRI) is a non-invasive method of assessing PWV. Assessing maternal influences on offspring PWV is important as reduced fetal nutrient supply and impaired early development are linked with an increased risk of cardiovascular disease in adulthood. In multiparous women, changes in the uterine spiral arteries arising during previous pregnancies result in increased fetal nutrient supply. Rat studies have shown that changes in maternal fatty acid intake in pregnancy are associated with increased offspring arterial stiffness. Some studies of human adults suggest omega- 3 fish oils reduce arterial stiffness. The objective of the study was to measure vascular stiffness using MRI, and examine maternal influences on vascular structure in children aged 9 years.

\section{Methods}

Aortic PWV was assessed in 125 children aged 9 years (70 male, 55 female) using velocity-encoded MRI as part of a study of developmental influences on cardiovascular structure and function. Maternal diet had been assessed in early and late pregnancy, and the child's diet at age 9 years, using administered food frequency questionnaires.

${ }^{1} \mathrm{NIHR}$ Biomedical Research Centre in Nutrition, Southampton, UK Full list of author information is available at the end of the article

\section{Results}

PWV values fell within previously reported childhood ranges. Childhood aortic PWV was lower in offspring of multiparous mothers $(3.32 \mathrm{~m} / \mathrm{sec}$, vs $3.45 \mathrm{~m} / \mathrm{sec}$ in offspring of primiparous mothers, $\mathrm{p}=0.05)$. Higher maternal oily fish intake in pregnancy was associated with lower childhood aortic PWV (early pregnancy oily fish $\mathrm{r}=-0.19, \mathrm{p}=0.047, \mathrm{n}=106$, late pregnancy oily fish $\mathrm{r}=-$ $0.25, \mathrm{p}=0.005, \mathrm{n}=125$, adjusting for child's sex), but there was no association with the child's current fish intake.

\section{Conclusions}

MRI measurements of childhood aortic PWV indicate that the mother's parity, and normal variations in maternal oily fish intake in pregnancy, may alter vascular development in utero - changing arterial structure and function with long-term consequences for cardiovascular risk in later life.

\section{Funding}

This work was supported by funding from the British Heart Foundation and the National Institute for Health Research (Southampton NIHR Nutrition, Diet \& Lifestyle Biomedical Research Unit).

\footnotetext{
Author details

${ }^{1} \mathrm{NIHR}$ Biomedical Research Centre in Nutrition, Southampton, UK. ${ }^{2}$ Cadiothoracic Radiology, Southampton University Hospitals NHS Trust, Southampton, UK. ${ }^{3}$ Institute of Developmental Sciences, Southampton, UK. ${ }^{4}$ MRC Lifecourse Epidemiology Unit, University of Southampton, Southampton, UK.
} 
doi:10.1186/1532-429X-14-S1-T8

Cite this article as: Bryant et al: Magnetic resonance imaging of pulse wave velocity in children aged 9 years to assess maternal influences on aortic stiffness in the offspring. Journal of Cardiovascular Magnetic Resonance 2012 14(Suppl 1):T8.

Submit your next manuscript to BioMed Central and take full advantage of:

- Convenient online submission

- Thorough peer review

- No space constraints or color figure charges

- Immediate publication on acceptance

- Inclusion in PubMed, CAS, Scopus and Google Scholar

- Research which is freely available for redistribution

Submit your manuscript at www.biomedcentral.com/submit
() Biomed Central 